\title{
ANALISIS SERVICE EXPERIENCE PADA PENGGUNA TRANSPORTASI BUS WISATA MPOK SITI (BUS JAKARTA EXPLORER)
}

\author{
Firra Kholisha Mustika, Fahrurozy Darmawan*, Devi Roza K. Kausar \\ Fakultas Pariwisata, Universitas Pancasila \\ Srengseng Sawah, Jagakarsa, Jakarta Selatan 12640, Indonesia \\ Email: $\underline{\text { dfahrurozy@gmail.com } \mid * K o r e s p o n d e n s i ~}$
}

\begin{abstract}
Mpok Siti Tourism Bus (Jakarta Explorer Bus) is a realization of the DKI Jakarta Provincial Government to supporting and developing the tourism sector. The tour bus offers a tour service experience around the city of Jakarta. Service experience theory has 7 dimensions, namely; incentive, accessibility, convenience, utility, environment, benefits and trust (Knutson, 2006). The purpose of this study is first to identify the level of suitability and performance of service experience, secondly this paper analyze the service experience that obtained by Mpok Siti Tourism Bus users. The study design uses descriptive quantitative methods through purposive sampling with the number of respondents 100 sample. Data processing techniques using importance performance analysis using Excel program and SPSS 22.0. The analysis results are the suitability level between interests and performance of 96 percent with the highest dimension of incentive and trust by 98 percent and the lowest dimension of accessibility by 84 percent. From the survey it is also known that Mpok Siti Tourism Bus users do not consider education dimension important in traveling. This is indicated by the higher importance score on travel ease and physical factors of the bus, compared to the education dimension. Keywords: Tourist Transportation, Mpok Siti Tourist Bus, Service Experience, Tourism
\end{abstract}

\begin{abstract}
Abstrak
Bus Wisata Mpok Siti (Bus Jakarta Explorer) merupakan realisasi pemerintah Provinsi DKI Jakarta dalam mendukung serta mengembangkan sektor pariwisata melalui kemudahan aksesibilitas. Bus wisata tersebut menawarkan service experience tur berkeliling kota Jakarta. Teori service experience mempunyai 7 dimensi, yaitu; incentive, accessibility, convenience, utility, environment, benefit dan trust (Knutson, 2006). Tujuan dari penelitian ini pertama untuk menidentifikasi tingkat kesesuaian dan kinerja service experience, kedua untuk menganalisis service experience yang diperoleh pengguna Bus Wisata Mpok Siti. Desain penelitian menggunakan metode kuantitatif deskriptif melalui purposive sampling dengan jumlah responden sebanyak 100 orang. Teknik pengolahan data menggunakan importance performance analysis dibantu program excel dan SPSS 22.0. Hasil analisis yang diperoleh yaitu tingkat kesesuaian antara kepentingan dan kinerja sebesar 96 persen dengan dimensi tertinggi incentive dan trust sebesar 98 persen dan dimensi terendah accessibility sebesar 84 persen. Dari survey diketahui pula bahwa pengguna Bus Wisata Mpok Siti belum menganggap penting nilai edukasi dalam berwisata. Hal ditunjukkan dari skor kepentingan yang lebih tinggi pada kemudahan berwisata dan faktor fisik (kondisi) bus, dibandingkan pada unsur edukasi.

Kata kunci: Transportasi Wisata, Bus Wisata Mpok Siti, Service Experience, Pariwisata
\end{abstract}

\section{PENDAHULUAN}

DKI Jakarta merupakan ibu kota negara Indonesia yang sekaligus menjadi pusat pemerintahan. Perkembangan pesat infrastruktur dan teknologi berada didalamnya, sehingga sebagian orang memilih DKI Jakarta menjadi destinasi tujuan berwisata. Perkembangan infrastruktur Kota DKI Jakarta saat ini semakin pesat, setelah tahun 2018 terselengaranya event Asian games. Fasilitas umum, infrastruktur dan kendaraan moda transportasi diperbaiki guna menunjang acara tersebut. 
Pemerintah Provinsi DKI Jakarta berupaya menggiatkan pariwisata di Kota Jakarta dan bentuk keseriusannya tercantum dalam Peraturan Daerah Provinsi Daerah Khusus Ibukota Jakarta Nomor 6 Tahun 2015 Tentang Kepariwisataan. Salah satu strategi Pemerintah Provinsi DKI Jakarta dalam mendukung serta mengembangkan sektor pariwisata, dengan mempermudah aksesibilitas pariwisata melalui program penyediaan sarana transportasi wisata, maka pada tahun 2014 pemerintah Provinsi DKI Jakarta mengeluarkan Peraturan Gubernur Nomor 280 Tahun 2014 tentang Pembentukan, Organisasi dan Tata Kerja Unit Pengelola Jakarta Smart City. Kebijakan ini diharapkan dapat memperbaiki pelayanan publik di Provinsi DKI Jakarta. Salah satu agendanya melalui Smart Mobility for Smart City (Adhitya, 2017).

Peran transportasi dalam bidang pariwisata tidak hanya merupakan alat untuk bergerak dari satu tempat ke tempat yang lain. Transportasi dalam bidang pariwisata dapat digunakan untuk membentuk suatu daya tarik (Hall dalam Novitasari, 2016). Umumnya wisatawan mencari suatu pengalaman dari perjalanan yang dilakukan pada lokasi wisata yang dikunjungi. Pengalaman perjalanan yang ditawarkan oleh sarana transportasi pariwisata harus menjadi bagian integral dalam pembuatan kebijakan desain penyediaan transportasi pariwisata (Lumsdon, 2006).

Sistem transportasi yang baik dapat dilihat dari empat elemen yaitu sarana penghubungnya, terminal, kendaraan serta manajemen dan tenaga kerja (C. Jotin Khisty dan B. Kent lall dalam Fadilla, 2018).

Poon dalam Saputra (2016) berpendapat, saat ini terjadi perubahan consumers behaviour pattern atau pola konsumsi dari para wisatawan. Mereka tidak lagi terfokus hanya ingin santai dan menikmati sun, sea and sand, saat ini pola konsumsi mulai berubah ke jenis wisata yang lebih tinggi, yang meskipun tetap santai tetapi dengan selera yang lebih meningkat yakni menikmati produk atau kreasi budaya (culture) dan peninggalan sejarah (heritage) serta nature atau eko-wisata dari suatu daerah atau negara. Sejalan dengan fungsi operasional Bus Wisata Mpok Siti yang mengajak pengguna berkeliling destinasi wisata kota dan terjadinya perubahan pola konsumsi wisatawan yang disebutkan Poon diatas, perlu dikaji kembali mengenai informasi maupun tindakan petugas bus dalam memberikan pengalaman berwisata berupa pelayanan jasa.

Pendekatan teori yang digunakan service experience menurut Knutson, Beck, Hyun Kim, dan Cha (2007) memiliki dimensi antara lain, incentive, accessibility, convenience, utility, environment, benefit, dan trust, teori ini diperkuat oleh penelitian Sari (2011) yang juga meneliti service experience pada kereta api wisata. Teori service experience pada penelitian ini akan dianalisis berdasarkan kepentingan (importance) pengguna Bus Wisata Mpok Siti dan kinerja (performance) dari Bus Wisata Mpok Siti.

Penelitian ini bertujuan untuk mengidentifikasi tingkat kesesuaian dan kinerja service experience transportasi Bus Wisata Mpok Siti serta menganalisis service experience yang diperoleh pengguna transportasi Bus Wisata Mpok Siti.

\section{METODE}

Penelitian ini akan berlangsung area rute Bus Wisata Mpok Siti; BW1 - Sejarah Jakarta (History of Jakarta) dan BW3 - Kesenian dan Kuliner (Art and Culinary). Penelitian ini menggunakan metode deskriptif dengan pendekatan kuantitatif. Sifat umum penelitian kuantitatif, antara lain: (a) kejelasan unsur: tujuan, subjek, sumber data sudah mantap, dan rinci sejak awal, (b) dapat menggunakan sampel, (c) kejelasan desain penelitian, dan (d) analisis data dilakukan setelah semua data terkumpul (Arikunto, 2006). Penelitian deskriptif yaitu, penelitian yang dilakukan untuk mengetahui nilai variabel mandiri, baik satu variabel atau lebih (independen) tanpa membuat perbandingan, atau menghubungkan dengan variabel yang lain menurut (Sugiyono, 2012).

\section{Jenis dan Sumber Data}

Berdasarkan sumber data yang akan dikaji dalam penelitian ini dibagi menjadi dua, yaitu:

1. Data primer, diperoleh melalui observasi awal bertujuan mengetahui kondisi lapangan untuk mempertajam landasan penelitian dan penyebaran angket (kuisioner) kepada pengguna Bus Wisata Mpok Siti.

2. Data sekunder, diperoleh melalui tinjauan literatur terdahulu seperti jurnal, skripsi, tesis, dan buku-buku, serta data terkait Bus Wisata Mpok Siti kepada PT. Transportasi Jakarta. 


\section{Definisi Operasional Variabel}

Definisi operasional adalah suatu definisi mengenai variabel yang dirumuskan berdasarkan karakterisik-karakterisik variabel tersebut yang dapat diamati (Azwar, 2007). Variabel yang digunakan dalam penelitian ini hanya satu dengan tujuh sub variabel dan menggunakan indikator yang disesuaikan pada penelitian sebelumnya (Sari, 2011) yaitu teori service experience. Pengukuran yang digunakan dalam penelitian ini menggunakan instrumen Importance Performance Analysis (IPA). Dijelaskan oleh Thtersia (2015), Importance Performance Analysis merupakan metode yang memetakan persepsi pelanggan terhadap tingkat kepentingan (importance) aspek pelayanan dengan persepsi pelanggan terhadap kinerja (performance) dari aspek pelayanan untuk mengidentifikasi layanan yang perlu ditingkatkan. Penelitian ini menggunakan bobot skala Likert dibantu dengan Microsoft Exel dan SPSS 22.0.

\section{Metode Pengumpulan Data}

1. Observasi

2. Penyebaran Angket

3. Dokumentasi

4. Tinjauan Literatur

\section{Tehnik Penentuan Responden}

Penentuan responden untuk penelitian ini menggunakan teknik non probability sampling melalui purposive sampling. Responden yang dimaksud dalam penelitian ini adalah pengguna Bus Wisata Mpok Siti dan individu yang sudah pernah menggunakan bus wisata.

\section{Analisis Data}

Ada dua macam, metode untuk menampilkan data IPA, yaitu: (1) menempatkan garis perpotongan kuadran pada nilai rata-rata sumbu tingkat kepuasan data terletak pada kuadran berapa; (2) menempatkan garis perpotongan kuadran pada nilai rata-rata hasil pengamatan pada sumbu tingkat kepuasan dan sumbu prioritas penanganan dengan tujuan untuk mengetahui secara spesifik masing-masing faktor terletak pada kuadran berapa (Martinez, 2003). Berikut prosedur berkaitan dengan penggunaan metode IPA:

1. Penentuan faktor-faktor yang akan dianalisa

2. Melakukan survei melalui angket
3. Menghitung nilai rata-rata tingkat kepuasan dan prioritas penanganan

4. Membuat grafik IPA

5. Melakukan evaluasi terhadap faktor sesuai dengan kuadran masing-masing.

\section{Validitas Data}

Diperlukan suatu alat ukur atau instrumen untuk mengetahui keabsahan dan kesahihan instrumen penelitian. Untuk mengatasi hal tersebut sebelum data diolah lebih lanjut maka diperlukan dua macam pengujian yaitu test of reliability (uji keandalan) dan test of validity (uji validitas atau kesahihan) sebagai uji kesungguhan jawaban dari responden (Sekaran, 2003).

Suatu intrumen dianggap reliabel jika memiliki koefisiensi $(\alpha)$ sebesar 0,6 atau lebih. Dasar pengambilan keputusan menurut Sekaran (2003). Suatu indikator dipandang "valid" jika p-value $<$ alpha 0,05 (Hermawan, 2006).

\section{HASIL DAN PEMBAHASAN \\ Gambaran Umum Bus Wisata Mpok Siti}

Bus Wisata Mpok Siti yang merupakan julukan untuk Bus Jakarta Explorer. Bus ini dikelola oleh PT. Transportasi Jakarta. PT. Transportasi Jakarta resmi beroperasi sejak 1 Februari 2004. Pada 27 Maret 2014, resmi berganti nama menjadi PT. Transportasi Jakarta.

Pemerintah Provinsi DKI Jakarta menyadari bahwa masyarakat DKI Jakarta membutuhkan moda transportasi massa yang nyaman, aman serta terjangkau. Maka dari itu melalui Smart Mobility pemerintah DKI Jakarta bersama PT. Transportasi Jakarta mengembangkan produk layanan wisata yakni Bus Wisata Jakarta. Bus Wisata Jakarta adalah bus tingkat yang dikhususkan untuk kepentingan pelayanan wisata kota (Adhitya, 2017).

Awal mula Bus Wisata Jakarta berada di bawah Dinas Pariwisata DKI Jakarta yang kemudian pada tahun 2015, Basuki Tjahaya Purnama selaku Gubernur DKI Jakarta memindahkan Bus Wisata Jakarta kepada PT. Transportasi Jakarta. Beberapa armada bus wisata merupakan hibah sumbangan dari perusahaan dalam bentuk CSR (Corporate Social Responsibility) dan sesuai dengan SPM (Standar Pelayanan Minimum) yang telah ditetapkan oleh pemerintah. 
Awal mula bus wisata mempunyai empat rute dan saat ini rute tersebut sudah ditambahkan menjadi tujuh rute. Setiap bus wisata beroperasi pada pukul 10.00 WIB - 18.00 WIB hari Senin - Sabtu dan pukul 12.00 WIB - 19.00 WIB hari Minggu (gambar 4.3). Khusus untuk rute BW 3 beroperasi hanya dari Sabtu pukul 17.00 WIB 23.00 WIB. Sesuai namanya Art and culinary, rute ini dioperasikan pada malam hari dengan tujuan memperkenalkan wisata kuliner malam sekitar rute tersebut. Jalur yang dilewati rute ini merupakan gabungan dari rute BW 1 dan BW 2. Selanjutnya arah jalur bus ditentukan oleh team tour leader yang berada pada empat titik (BNI, Kalijodo, Irti Monas dan Masjid Istiqlal) pemberhentian bus wisata.

Setiap penumpang yang hendak menggunakan bus wisata, petugas membagikan tiket. Tiket ini berfungsi sebagai laporan petugas kepada PT. Transportasi Jakarta untuk mengetahui jumlah penumpang bus wisata. Harga yang seharusnya dibayarkan oleh pengguna bus wisata sebesar Rp. 12.000,- sampai Rp 15.000,-. Namun harga tiket tersebut ditanggung oleh Pemda DKI Jakarta.

\section{Karakterisik Demografi Responden}

Pada penelitian ini peneliti membagikan data kuisioner kepada 100 orang responden, disesuaikan dengan perhitungan rumus Slovin. Responden adalah pengguna bus wisata Mpok Siti dan individu yang sudah menggunakan bus wisata. Kuisioner dibagikan secara langsung dan online. Hasil pengamatan peneliti mengenai karakterisik demografi pengguna Bus Wisata Mpok Siti yang dijelaskan pada tabel 1. Data ini diambil padaa bulan Juni dan Juli 2019.

Tabel 1. Karakterisik Demografi Responden

\begin{tabular}{|c|c|c|}
\hline \multicolumn{2}{|c|}{ Karakterisik Responden } & $\begin{array}{c}\text { Jumlah dalam } \\
\text { persentase (\%) }\end{array}$ \\
\hline \hline \multirow{2}{*}{$\begin{array}{c}\text { Jenis } \\
\text { Kelamin }\end{array}$} & Laki-laki & $47 \%$ \\
\cline { 2 - 3 } & Perempuan & $53 \%$ \\
\hline \multirow{4}{*}{ Usia } & $13-17$ Tahun & $4 \%$ \\
\cline { 2 - 3 } & 18 Tahun & $9 \%$ \\
\cline { 2 - 3 } & $18-40$ Tahun & $71 \%$ \\
\cline { 2 - 3 } & $40-60$ Tahun & $16 \%$ \\
\cline { 2 - 3 } & $>60$ tahun & $0 \%$ \\
\hline
\end{tabular}

\begin{tabular}{|c|c|c|}
\hline \multicolumn{2}{|c|}{ Karakterisik Responden } & \multirow{2}{*}{$\begin{array}{c}\text { Jumlah dalam } \\
\text { persentase }(\%)\end{array}$} \\
\hline \multirow{6}{*}{$\begin{array}{l}\text { Pendidikan } \\
\text { Terakhir }\end{array}$} & SD & \\
\hline & SMP & $19 \%$ \\
\hline & SMA/SMK & $37 \%$ \\
\hline & D3 & $23 \%$ \\
\hline & S1/D4 & $12 \%$ \\
\hline & $>\mathrm{S} 1$ & $2 \%$ \\
\hline \multirow{6}{*}{ Pekerjaan } & Pelajar/Mahasiswa & $58 \%$ \\
\hline & Pedagang & $0 \%$ \\
\hline & Wiraswata & $6 \%$ \\
\hline & PNS & $4 \%$ \\
\hline & Swasta & $21 \%$ \\
\hline & Lainnya & $12 \%$ \\
\hline \multirow{6}{*}{$\begin{array}{c}\text { Asal } \\
\text { Daerah }\end{array}$} & JABODETABEK & $84 \%$ \\
\hline & Jawa Tengah & $6 \%$ \\
\hline & Jawa Barat & $4 \%$ \\
\hline & Jawa Timur & $1 \%$ \\
\hline & Luar Jawa & $5 \%$ \\
\hline & Mancanegara & $0 \%$ \\
\hline \multirow{4}{*}{$\begin{array}{c}\text { Jumlah } \\
\text { Kunjungan }\end{array}$} & 1 kali & $76 \%$ \\
\hline & 2 kali & $8 \%$ \\
\hline & 3 kali & $6 \%$ \\
\hline & $>3$ kali & $11 \%$ \\
\hline \multirow{5}{*}{$\begin{array}{c}\text { Alasan } \\
\text { Kunjungan }\end{array}$} & Mencoba bus wisata & $39 \%$ \\
\hline & $\begin{array}{l}\text { Keliling Jakarta } \\
\text { dengan gratis }\end{array}$ & $23 \%$ \\
\hline & Menikmati waktu luang & $17 \%$ \\
\hline & Lainnya & $12 \%$ \\
\hline & $\begin{array}{c}\text { Belajar dan mencari } \\
\text { pengalaman baru }\end{array}$ & $9 \%$ \\
\hline
\end{tabular}

Sumber: Peneliti (2019)

\section{Analisis Tingkat Kesesuaian}

Suatu industri barang maupun jasa perlu mengetahui sejauh mana produk mereka diterima oleh konsumen. Sehingga, tingkat kepuasan pelanggan perlu diukur dalam kaitannya dengan apa yang seharusnya dikerjakan oleh perusahaan agar menghasilkan barang atau jasa yang berkualitas tinggi. Dalam penelitian ini, kualitas pelayanan pengalaman berwisata pengguna Bus Wisata Mpok Siti dikelompokan berdasarkan tujuh dimensi service experience, yaitu; incentive, accessibility, convenience, utility, environment dan trust. 
Kemudian, masing-masing variabel dijabarkan dalam bentuk pertanyaan yang berkaitan dengan kepentingan dan kinerja penyampaian service experience oleh Bus Wisata Mpok Siti. Untuk mengidentifikasi kualitas kinerja pelayanan pengalaman berwisata pengguna Bus Wisata Mpok Siti sudah sesuai harapan atau belum, penelitian ini menggunakan importance performance analysis dengan melakukan perhitungan tingkat kesesuaian. Tingkat kesesuaian dihitung nilai peratribut yang kemudian dijumlah dan dicari rata-ratanya, setelah itu hasil dituliskan dalam bentuk persentase. Sedangkan untuk menganalisis service experience yang dirasakan oleh pengguna setelah menggunakan Bus Wisata Mpok Siti, digambarkan dengan diagram kartesius yang terbagi menjadi empat kategori.

Tabel 2. Rata-rata perhitungan persentase tingkat kesesuaian ketujuh dimensi service experience

\begin{tabular}{|l|c|c|c|}
\hline \multicolumn{1}{|c|}{ Dimensi } & $\begin{array}{c}\text { Mean } \\
\text { Importance }\end{array}$ & $\begin{array}{c}\text { Mean } \\
\text { Performance }\end{array}$ & $\begin{array}{c}\text { Tingkat } \\
\text { Kesesuaian }\end{array}$ \\
\hline \hline Incentive & 3,78 & 3,74 & $98 \%$ \\
\hline Accessibility & 3,93 & 3,34 & $84 \%$ \\
\hline Convenience & 4,07 & 3,61 & $88 \%$ \\
\hline Utility & 4,14 & 3,61 & $87 \%$ \\
\hline Environment & 3,82 & 3,43 & $89 \%$ \\
\hline Benefit & 4,44 & 4,05 & $91 \%$ \\
\hline Trust & 3,86 & 3,78 & $98 \%$ \\
\hline \hline $\begin{array}{c}\text { Rata-rata } \\
\text { Keseluruhan }\end{array}$ & $\mathbf{4 , 0 0}$ & $\mathbf{3 , 8 8}$ & $\mathbf{9 6 \%}$ \\
\hline
\end{tabular}

Sumber: Peneliti (2019)

Dalam menentukan kualitas service experience pada pengguna Bus Wisata Mpok Siti dilakukan perhitungan kepentingan (harapan layanan yang diterima) dan kinerja penyedia jasa. Nilai yang diperoleh mencerminkan kualitas layanan tingkat kesesuaian dalam bentuk persentase. Sesuai Tabel 2. rata-rata tingkat kesesuaian ketujuh dimensi sebesar 88 persen. Dimensi yang memperoleh nilai tertinggi adalah utility sebesar $96 \%$ dan dimensi terendah adalah trust sebesar $83 \%$.

\section{Importance Performance Analysis Service Experience Pada Pengguna Bus Wisata Mpok Siti}

Analisis pemetaan prioritas dalam penelitian ini dituangkan dalam diagram kartesius pada gambar 1. Data yang ditabulasi ke dalam gambar diagram kartesius tersebut diolah menggunakan SPSS 22. Berikut adalah hasil pemetaan prioritas service experience pada pengguna Bus Wisata Mpok Siti:

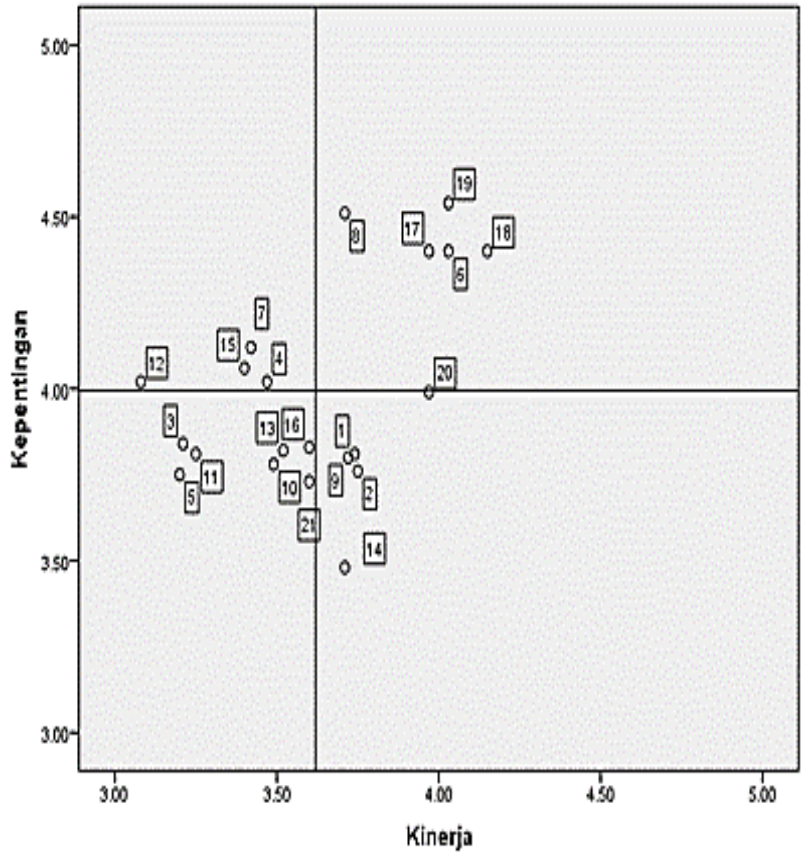

Gambar 1. Diagram kertesius service experience pengguna Bus Wisata Mpok Siti Sumber: peneliti (2019)

Uraian gambar 1 diatas menunjukkan hasil pemetaan atribut dua puluh satu butir pertanyaan mengenai ketujuh dimensi service experience yang dirasakan oleh pengguna Bus Wisata Mpok Siti. Hasil yang tertera pada diagram kartesius diatas yaitu; lima titik berada pada kuadran A, lima titik berada pada kuadran B, lima titik berada pada kuadran $\mathrm{C}$ dan enam titik berada pada kuadran D. Adapun rumus untuk menghitung letak titik potong pada gambar diagram karesius di atas sebagai berikut:

$$
\begin{array}{ll}
\bar{x}=\frac{\sum X i}{n} & \bar{Y}=\frac{\sum Y i}{n} \\
\bar{x}=\frac{76}{21}=3,61 & \bar{y}=\frac{83,87}{21}=3,99
\end{array}
$$


Kuadran A adalah prioritas utama dimana pengguna Bus Wisata Mpok Siti sebagai responden merasakan atribut tersebut sangat penting dan mempunyai harapan tinggi namun belum merasakan kinerja yang maksimal. Adapun atribut tersebut: 1. Butir pertanyaan nomor empat (4), dimensi accessibility: Bus wisata sudah mempunyai waktu keberangkatan terjadwal sehingga memudahkan pengguna dalam menentukan waktu berwisata.

2. Butir pertanyaan nomor tujuh (7), dimensi utility: Bus Wisata Mpok Siti memberikan kepraktisan dalam melakukan city sightseeing di Kota Jakarta.

3. Butir pertanyaan nomor dua belas (12), dimensi environment: Papan interpretasi pada halte Bus Wisata Mpok Siti mudah dipahami dan informatif.

4. Butir pertanyaan nomor lima belas (15), dimensi environment: dilengkapi dengan air conditioner yang memberikan kenyamanan saat berada di dalam Bus Wisata Mpok Siti.

Kuadran B menunjukkan atribut layanan yang juga dianggap penting pengguna Bus Wisata Mpok Siti dan kinerjanya sudah dianggap baik, oleh karena itu PT. Transportasi Jakarta harus mempertahankan kinerja atribut ini. Dengan harapan terus menjadi lebih baik dan memenuhi apa yang menjadi kebutuhan pengguna bus wisata. Adapun atribut yang digambarkan dalam kuadran $\mathrm{B}$, yaitu:

1. Butir pertanyaan nomor enam (6), dimensi convenience: pengguna Bus Wisata Mpok Siti dapat langsung menunggu di halte-halte bus wisata untuk melakukan city sightseeing tanpa perlu memesan tiket keberangkatan.

2. Butir pertanyaan nomor delapan (8), dimensi utility: kinerja layanan pengemudi bus dalam kemampuan mengemudi secara safety.

3. Butir pertanyaan nomor tujuh belas (17), dimensi benefit: Mendapatkan pengalaman berkesan selama di perjalanan dan setelah di perjalanan.

4. Butir pertanyaan nomor delapan belas (18), dimensi benefit: pengguna bus dapat keuntungan untuk wisata berkeliling kota Jakarta dengan tarif gratis tanpa berpindah transportasi.

5. Butir pertanyaan nomor sembilan belas (19), dimensi benefit: Manfaat informasi rute yang dilalui Bus Wisata Mpok Siti dari desain exterior bus
6. Butir pertanyaan nomor dua puluh (20), dimensi trust: konten informasi mengenai Bus Wisata Mpok Siti yang berada di website lengkap dan sesuai.

Kuadran C menunjukkan pengguna bus wisata tidak mempunyai harapan terlalu tinggi sehingga kinerja yang diberikan juga memperoleh penelitian rendah. Dengan demikian perlu dipertimbangkan oleh PT. Transportasi Jakarta terkait perbaikan pelayanan pada kuadran ini. Adapun atribut yang digambarkan dalam kuadran $\mathrm{C}$, yaitu:

1. Butir pertanyaan nomor tiga (3), dimensi acessibility: informasi mengenai Bus Wisata Mpok Siti berada di halte-halte bus wisata sehingga orang-orang yang berada di halte dapat mengetahui keberadaan halte wisata.

2. Butir pertanyaan nomor lima (5), dimensi convenience: Informasi mengenai Bus Wisata Mpok Siti dapat diperoleh pada halte-halte bus wisata, akun media sosial dan web site PT. Transportasi Jakarta.

3. Butir pertanyaan nomor sepuluh (10), dimensi environment: bus di desain tingkat menjadi salah satu keunikan yang berbeda dengan transportasi umum lainnya.

4. Butir pertanyaan nomor sebelas (11), dimensi environment: informasi berupa edukasi destinasi wisata yang dilalui oleh Bus Wisata Mpok Siti, pada halte-halte pemberhentian.

5. Butir pertanyaan nomor tiga belas (13), dimensi environment: kondisi kebersihan bus membuat pengguna dapat melihat jelas lokasi wisata yang berada di sepanjang rute perjalanan dan kondisi kelayakan bangku.

6. Butir pertanyaan nomor enam belas (16), dimensi environment: Bus Wisata Mpok Siti terdapatkan seorang pemadu wisata yang kompeten selama memberikan informasi.

7. Butir pertanyaan nomor dua puluh satu (21), dimensi trust: PT. Transportasi Jakarta berusaha untuk membangun kepercayaan pengguna terhadap produk dan jasa yang ditawarkan Bus Wisata Mpok Siti sebagai transportasi wisata.

Kuadran D menunjukkan keberadaan atribut layanan yang menurut pengguna bus wisata kinerjanya sudah baik bahkan cenderung melebihi keinginan 
pengguna, karena sebenarnya tidak terlalu mempunyai harapan pada atribut layanan ini. Adapun atribut yang digambarkan dalam kuadran $\mathrm{D}$, yaitu:

1. Butir pertanyaan nomor satu (1), dimensi incentive: usaha mencapai lokasi yang dilakukan sesuai dengan pengalaman yang didapat setelah menggunakan bus wisata.

2. Butir pertanyaan nomor dua (2), dimensi incentive: bus wisata tetap konsisten memberikan pelayanan yang baik dengan penetapan tarif gratis.

3. Butir pertanyaan nomor Sembilan (9), dimensi utility: keamanan dan kenyamanan di dalam Bus Wisata Mpok Siti menjadi prioritas utama yang diberikan untuk pengguna bus wisata.

4. Butir pertanyaan nomor empat belas (14), dimensi environment: speaker Bus Wisata Mpok Siti terdengar jelas pada seluruh area bus.

Berdasarkan hasil penjabaran kuadran diatas, kuadran yang mempunyai penilaian kinerja rendah adalah kuadran A, kuadran yang sudah sesuai dengan harapan pengguna Bus Wisata Mpok Siti sehingga memperoleh penilaian kinerja baik adalah kuadran B dan kuadran yang belum sesuai dengan harapan pengguna bus wisata sehingga memperoleh nilai kinerja rendah adalah kuadran $\mathrm{C}$.

Penjabaran mengenai atribut pada kuadran A yang merupakan prioritas utama tetapi kinerja dinilai rendah dapat peneliti analisis sebagai berikut; pertama, waktu keberangkatan Bus Wisata Mpok Siti tidak dapat dijadwalkan karena jalanan Ibu Kota Jakarta yang macet mengakibatkan pengguna bus dapat menunggu pada halte pemberhentian 10 sampai 30 menit. Berdasarkan hasil kuisioner penelitian pengguna bus mayoritas baru pertama kali (tabel 1.) menggunakan Bus Wisata Mpok Siti dan papan interpretasi di halte pemberhentian tidak informatif. Kondisi tersebut mengakibatkan Bus Wisata Mpok Siti yang semula bertujuan memberikan kepraktisan dalam melakukan city sightseeing mendapat penilaian rendah. Ketiga, wisatawan lebih banyak menggunakan Bus Wisata Mpok Siti pada siang hari, sehingga waktu yang lama saat menunggu di halte pemberhentian membuat sebagian besar responden kurang merasakan dari kinerja air conditioner.

Berdasarkan teori kualitas jasa menurut Lewis dan Booms (1983 dalam Tjiptono, 2011)" merupakan ukuran seberapa bagus tingkat layanan yang diberikan mampu sesuai dengan ekspektasi pelanggan", atribut pertanyaan yang terdapat pada kuadran A belum sesuai dengan teori tersebut karena masih memperoleh penilaian kinerja rendah.

Analisis yang dapat peneliti ambil mengenai atribut service experience pengguna Bus Wisata Mpok Siti sehingga termasuk kuadran B, yaitu; pertama, adanya Bus Wisata Mpok Siti ini membantu setiap wisatawan untuk melalukan city sightseeing ke destinasi wisata Kota Jakarta. Kedua, wisatawan dapat berkeliling ke destinasi tujuan tanpa dikenakan biaya dengan pelayanan yang baik. Hal ini sesuai dengan tujuan utama sektor transportasi yang dikemukakan oleh Salim (2004) pelayanan jasa transportasi yang memadai terhadap tingkat kebutuhan dan pelayanan secara cepat, tepat, aman, teratur dan terjangkau oleh kemampuan masyarakat.

Ketiga, pengguna bus wisata yang didominasi pengunjung baru sudah merasakan kesan pengalaman perjalanan baik saat menggunakan Bus Wisata Mpok Siti. Diukur dari bus yang memenuhi standar safety, desain exterior yang menunjukkan rute bus dan penyebaran informasi yang mengikuti perkembangan teknologi. Uraian tersebut peneliti telaah dengan teori Lumsdon (2006), pengalaman perjalanan yang ditawarkan oleh sarana transportasi pariwisata harus menjadi bagian dalam pembuatan kebijakan desain penyediaan transportasi pariwisata.

Pada kuadran $\mathrm{C}$ menunjukkan titik atribut pertanyaan terbanyak sejumlah tujuh buah. Sehingga peneliti mengkaji kondisi tersebut guna kepentingan yang coba disampaikan pengelola Bus Wisata Mpok Siti dapat diterima oleh penggunanya. Kuadran ini dianalisis sebagai berikut; pertama, desain bus yang menggambarkan destinasi wisata Jakarta hanya beberapa bus saja, yaitu bus tingkat berbentuk kotak. Bus yang berbentuk kotak ini bukan sumbangan CSR. Mayoritas bus yang beroperasi adalah bus sponsor sehingga desain bus mengikuti iklan sponsor tersebut dan kaca bus terlihat buram oleh sticker mengakibatkan terganggunya pengguna melihat keluar kaca.

Kedua, setelah pengelolaan bus wisata dialihkan kepada PT. Tranportasi Jakarta, petugas yang semula ada empat orang (pengemudi, kondektur, polisi wisata, dan pemandu wisata) diubah menjadi dua orang (pengemudi dan pemandu wisata yang merangkap menjaga keamanan dan kondektur). 
Banyaknya tugas pemandu, menjadikan guiding yang diberikan belum maksimal. Selain alasan tersebut sesuai observasi peneliti, pemandu wisata tidak melakukan guiding sepanjang perjalanan karena posisi bus yang tingkat membuat interaksi petugas dengan penumpang tidak intensif serta penumpang yang tidak begitu ingin mengetahui guiding dari pemandu tetapi lebih sibuk berbincang dan berfoto.

Ketiga, informasi yang terdapat pada halte pemberhentian bus wisata belum maksimal. Kemajuan pendistribusian informasi melalui website dan media sosial menggeser perhatian PT. TransJakarta pada papan interpretasi di halte pemberhentian bus wisata. Jika peneliti kaitkan dengan teori Hall (1999 dalam Novitasari, 2016) transportasi dalam bidang pariwisata dapat digunakan untuk membentuk suatu daya tarik. Namun, pada kasus Bus Wisata Mpok Siti, desain bus yang bertingkat tidak menjadi alasan kuat bagi pengguna sebagai keunikan suatu daya tarik.

Keempat, alasan kunjungan responden pada tabel 1 sebesar 39 persen mencoba bus wisata dan 9 persen belajar dan mencari pengalaman baru. Dengan demikian PT. Transportasi Jakarta perlu melirik alasan tersebut, guna memberikan kepercayaan Bus Wisata Mpok Siti menjadi transportasi wisata yang bermanfaat bagi penggunanya.

Dengan demikian pergeseran pola konsumsi wisatawan yang dikemukakan Poon dalam Saputra (2016) belum sepenuhnya terjadi pada pengguna Bus Wisata Mpok Siti. Orientasi service experience yang dirasakan pengguna Bus Wisata Mpok Siti saat ini, yaitu kemudahan berwisata secara gratis dengan fasilitas bus yang baik, sedangkan nilai edukasi memperkaya diri seperti kreasi budaya (culture) dan peninggalan sejarah (heritage) masih kurang.

Hal ini juga dibuktikan pada tabel 2 dari ketujuh dimensi service experience, dimensi yang memiliki nilai kesesuaian tertinggi adalah dimensi incentive dan trust sebesar 98 persen. Kedua dimensi ini menjelaskan kepercayaan yang dibangun PT. Transportasi Jakarta untuk menggunakan Bus Wisata Mpok Siti dengan tarif gratis dan visualisasi informasi yang baik melalui website dan media sosial. Sedangkan dimensi yang memiliki nilai kesesuaian terendah adalah dimensi accessibility sebesar 84 persen. Kepercayaan pengguna untuk menggunakan Bus Wisata Mpok Siti setelah melihat visualisasi pada website dan media sosial belum terjadi kesesuaian. Hal ini dikarenakan kondisi macetnya jalanan Ibu Kota DKI Jakarta membuat jadwal keberangkatan bus tidak pasti dan pengguna dapat menunggu bus di halte pemberhentian cukup lama. Kurangnya informasi atau berita pengalih perhatian pada halte bus wisata.

\section{KESIMPULAN}

Penelitian ini dilakukan terhadap pengguna Bus Wisata Mpok Siti untuk mengidentifikasi service experience setelah menggunakan bus wisata. Maka kesimpulan untuk menjawab rumusan masalah yaitu tingkat kesesuaian antara harapan pengguna bus wisata dan kinerja Bus Wisata Mpok Siti memiliki angka rata-rata cukup baik sebesar 96 persen dengan dimensi tertinggi incentive dan trust sebesar 98 persen dan dimensi terendah accessibility sebesar 84 persen.

Sehingga service experience yang tertanam oleh pengguna bus wisata masih terfokus pada kemudahan berwisata dan daya tarik dari kondisi bus. Adanya Bus Wisata Mpok Siti ini membantu setiap wisatawan untuk melalukan city sightseeing ke destinasi wisata Kota Jakarta dengan tarif gratis, kondisi bus safety, desain exterior yang menunjukkan rute bus dan penyebaran informasi yang mengikuti perkembangan teknologi. Atributatribut tersebut terdapat pada kuadran A dan kuadran B.

Pengguna Bus Wisata Mpok Siti belum menganggap penting nilai edukasi dalam berwisata, (tabel 1) hanya 9 persen yang menyatakan belajar dan mencari pengalaman baru sebagai alasan berkunjung. Namun pada kenyataannya, kinerja yang diberikan pihak Bus Wisata Mpok Siti belum terfokus pada penyampaian nilai informasi edukasi di halte pemberhentian maupun guiding pemandu wisata. Atribut-atribut tersebut terdapat pada kuadran C.

PT. Transportasi Jakarta sebagai pihak pengelola Bus Wisata Mpok Siti dalam upaya memberikan service experience (pelayanan pengalaman) diperlukan pengkajian kembali mengenai program operasional untuk meningkatkan nilai pendistribusian informasi. Pertama, membagi pangsa pasar sesuai dengan kebutuhan, yaitu city sightseeing reguler (bebas biaya) dan city sightseeing premium (berbayar).

Selain itu perlu membuat program berdasarkan pembagian pangsa pasar tadi, city sightseeing reguler yaitu masyarakat yang ingin berkeliling 
destinasi kota Jakarta dengan gratis tetapi cukup membawa 3 jenis sampah (bekerjasama dengan dinas kebersihan dan lingkungan hidup) dan city sightseeing premium yaitu masyarakat yang ingin memperoleh nilai edukasi serta pengalaman lebih, tur premium ini hanya diadakan 3 jam dalam sehari dan 3 jam wisata malam hari Sabtu pada jalur BW 3, tur ini berhenti pada beberapa destinasi wisata dan adanya interaksi intens dengan pemandu wisata. Ketiga, membangun kembali citra Bus Wisata Mpok Siti sebagai transportasi wisata yang berbeda dengan transportasi umum dengan tagline explore Jakarta with Jakarta Explorer. Makna tagline tersebut adalah berkeliling destinasi wisata Kota DKI Jakarta dengan bus wisata, menggunakan bus wisata ikut menjaga lingkungan karena walaupun tarif gratis pengguna diharuskan membawa 3 jenis sampah, bus wisata memberikan nilai edukasi wisata dengan mengexplor/menggali cerita beberapa destinasi wisata Kota DKI Jakarta sehingga menjadikan bus wisata berbeda dengan transportasi umum.

Konsep program di atas peneliti uraikan berdasarkan kesimpulan penelitian yaitu ketertarikan pengguna dan kurangnya informasi edukasi pada bus wisata. Dengan harapan bus wisata dapat memberikan manfaat dan pengalaman berkesan bagi penggunanya setelah menggunakan bus wisata.

\section{DAFTAR PUSTAKA}

Adhitya, Febrian. 2017. Kebijakan Pemerintah DKI Jakarta Dalam Pelayanan Wisata Kota (Studi Terhadap Inovasi Bus Wisata Jakarta) [skripsi]. Jakarta (ID): Universitas Islam Negeri Syarif Hidayatullah.

Arikunto. 2006. Prosedur Penelitian Suatu Pendekatan Praktek. Jakarta: PT. Rineka Cipta.

Azwar, Saifuddin. 2007. Metode penelitian. Yogyakarta: Pustaka Belajar.

Hermawan, Asep. 2005. Penelitian Bisnis Paradigma Kuantitatif. Jakarta: Gramedia Widiasarana Indonesia.

Knutson, Bonnie J. Beck, Jeffrey A. Kim, Seung Hyun. Cha, Jaemin. 2007. Identifying The Dimensions of The Experience Construct. Journal of Hospitality \& Leisure Marketing, 15(3). The Haworth Press, Inc. [Internet]. [diakses2019Apr13]. Tersedia pada: http://jhlm.haworthpress.com.
Lumsdon, Les M. 2006. Factors Affecting The Design of Tourism Bus Service. Annals of Tourism Research. 3(3), 748-766.

Martinez, C. L. 2003. Evaluation Report: Tools Cluster Networking Meeting. Arizona: Center Point Institute, Inc.

Novitasari, Etika. 2016. Kualitas Pelayanan Bus Tingkat Wisata City Tour Jakarta sebagai Transportasi Khusus Pariwisata di Kota Jakarta [skripsi]. Yogyakarta (ID): Universitas Gadjah Mada.

Peraturan Daerah Provinsi Daerah Khusus Ibukota Jakarta Nomor 6 Tahun 2015 Tentang Kepariwisataan.

Salim, Abbas H.A. 2004. Manajemen Transportasi. Jakarta: PT. Raja Grafindo Persada.

Saputra, I Gede Gian Saputra Dan Sukana, I Made. 2016. Kajian Perilaku Wisatawan Eropa First Timer dan Repeater di Kelurahan Ubud. J Tourism Destination. 1(1).

Sari, Wulan, Wibowo, Lili Adi Dan Siswhara, Gita. 2011. Analisis Service Experience Dalam Menciptakan Kepuasan Penumpang Kereta Wisata Pt. Kereta Api Pariwisata (Survei Pada Wisatawan Domestik Kereta Wisata Bali, Kereta Wisata Toraja, Kereta Wisata Nusantara Pt. Kereta Api Pariwisata). J Tourism and Hospitality Essentials. 1(2).

Sugiyono. 2012. Metode Penelitian Kuantitatif Kualitatif dan R\&D. Bandung: Alfabeta.

Sekaran, Uma.2003. Research Method For Business: A Skill Building Approach. New York: John Wileyand Sons, Inc.

Setyoningsih, Lilis Dwi. 2005. Analisis Pengaruh Dimensi Kualitas Pelayanan Terhadap Kepuasan Toko Mall Luwes Palur Karanganyar [skripsi]. Surakarta(ID): Universitas Sebelas Maret.

Thtersia, Ifi Wilis. 2015. "Analisis Kualitas Pelayanan Dengan Menggunakan Gap Analysis dan IPA Pada Restoran Fusion Food" [skripsi]. Yogyakarta(ID): Universitas Gadjah Mada.

Tjiptono, Fandy. 2011. Service Management Mewujudkan Layanan Prima. Edisi 2. Yogyakarta: Andi.

Fadilla, Nur Dilla dan Darmawan, Fahrurozy. 2018. Pramuka Island Tourism Accessibility Transportation Development of the Thousand Island. Journal of Tourism Destination and Attraction, 6(2), 1-5.https://doi.org/10.35814/tourism.v6i2.769. 
Journal of Tourism Destination and Attraction 